\title{
ENTRE A AUTONOMIA E O CONTROLE: O SURGIMENTO DO INDIVÍDUO COMO CONDIÇÃO DE POSSIBILIDADE DOS SABERES E PRÁTICAS PSICOLÓGICOS $\star$
}

\author{
André Schmidt; Gabriel Gouvêa Monteiro; Filipe Carijó; \\ Karina Padilha; Maria Clara de Almeida; Miriam Starosky;

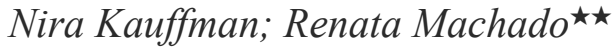 \\ Arthur Arruda Leal Ferreira ${ }^{\star \star \star}$
}

Palavras-chave: História da Psicologia. Indivíduo. Modernidade.

Ao contrário do que alguns imaginam, a noção de indivíduo não existe desde sempre, isto é, não se trata de algo universal e dado desde que o homem se reconhece como tal. A noção de indivíduo como um valor social, como uma categoria existencial é algo historicamente constituído.O que queremos mostrar neste estudo é quais foram as condições históricas que possibilitaram o surgimento do indivíduo e sua tomada como valor mais precioso na sociedade moderna, e como a invenção do indivíduo ocupa um lugar relevante na história do surgimento da psicologia. Este saber surge, a partir do século XIX, não como fruto de uma única origem, mas como resultado de diversas mudanças no campo das práticas sociais - dentre as quais o surgimento do indivíduo. Para este estudo, partimos da revisão bibliográfica de fontes secundárias - a partir da leitura de autores tais como Luis Dummont, Luiz Cláudio Figueiredo, Jean Pierre Vernant, Norbert Elias, e principalmente, Michel Foucault e Nikolas Rose. Durante a antiguidade e boa parte da idade média eram raras as experiências de individualização no campo social, pois na organização hierárquica da sociedade havia pouco espaço para mobilidade. Graças à estruturação jurídica dos Estados Modernos, temos no início da modernidade (século XVI) a constituição de indivíduos autônomos, singulares, iguais juridicamente e dotados de foro íntimo. Surge o indivíduo soberano regulado pela lei. Com o aumento da população, o inchaço das cidades, a invenção de novas técnicas, e as novas relações de produção baseadas no trabalho contratual, surge a demanda por uma nova tecnologia de poder, que não mais se basearia na lei, mas sim na vigilância constante dos indivíduos. O Estado, neste momento, passa a ter interesse pela vida dos cidadãos e a preocupação com a gestão desta vai constituir os saberes médicos e psicológicos. Esta experiência de individualização marcaria não apenas a psicologia funcional, que seria gestada nos Estados Unidos a partir do fim do século XIX, mas toda a prática psicológica, oscilando entre a busca de

\footnotetext{
^ Evento: V CONGRESSO NORTE-NORDESTE DE PSICOLOGIA, realizado em Maceió-AL, no Centro Cultural e de Exposições de Maceió, no período de 23 a 26 de maio de 2007.

$\star \star$ Alunos de graduação do Instituto de Psicologia

$\star \star \star$ Doutor em Psicologia (Psicologia Clínica) pela Pontifícia Universidade Católica de São Paulo. Atualmente é professor adjunto III da Universidade Federal do Rio de Janeiro. Endereço: Universidade Federal do Rio de Janeiro, Instituto de Psicologia, Departamento de Psicologia Geral e Experimental. Avenida Pasteur 250 - Pavilhão Nílton Campos - Praia Vermelha. CEP.: 22290240 - Rio de Janeiro, RJ - Brasil.

E-mail: arleal@superig.com.br
} 
autonomia e controle dos seus sujeitos. Assim se estabelece uma das tensões que dispersam os saberes psicológicos: alguns sistemas psicológicos irão valorizar a autonomia do indivíduo operando, contudo, controles (como os construtivistas, gestaltistas, humanistas); enquanto outros partirão da disciplina para constituição do indivíduo autônomo - como faz o behaviorismo. Algumas psicologias, pois mesmo que privilegiem a autonomia do ser humano, remetem-no a uma norma; outras, ainda que tentem disciplinar os sujeitos, fazem-no de modo a favorecer o seu autocontrole autônomo. Sem essa dicotomia moderna entre individuo autônomo x controlado talvez nem houvesse psicologia; pois uma vez que o indivíduo fosse pensado unicamente como autônomo não poderíamos tomá-lo como objeto de estudo. Ao passo que se houvesse apenas determinações, cairíamos no fatalismo e não seria necessária nenhuma intervenção psicológica.

Financiamento: FUJB e FAPERJ. 